\title{
Use of powder silicon as a photocurable resin filler for laser stereolithography and prospects for transforming stereolithographic parts with silicon from polymeric to ceramic ones.
}

\section{Michael Markov ( $\sim$ Lc250@mail.ru )}

Institut problem lazernyh i informacionnyh tehnologij RAN https://orcid.org/0000-0002-6310-9033

Vyacheslav Vnuk

Institut problem lazernyh i informacionnyh tehnologij RAN

Evgeny Ippolitov

Institut problem lazernyh i informacionnyh tehnologij RAN

Sergey Kamaev

Institut problem lazernyh i informacionnyh tehnologij RAN

Svetlana Cherebylo

Institut problem lazernyh i informacionnyh tehnologij RAN

\section{Research Article}

Keywords: laser stereolithography, additive technologies, silicon, silicon oxide, silicon carbide

Posted Date: March 31st, 2020

DOI: https://doi.org/10.21203/rs.3.rs-19918/v1

License: (c) (i) This work is licensed under a Creative Commons Attribution 4.0 International License.

Read Full License 


\section{Abstract}

The article deals with the peculiarities of using silicon micropowder as a chemically inert filler when creating photocurable resins (PCR) for laser stereolithography. The authors provide the results of their experiments on making three-dimensional parts from such resins and discuss the feasibility of transforming the parts from polymeric, containing a filler, into ceramic ones through annealing. The use of silicon allows for a two-fold increase in the mass of the ceramic component due to the interaction of silicon with air oxygen and with products resulting from the thermal decomposition of the photopolymer's polymer base.

\section{Introduction}

The current level of additive technologies development offers several methods of obtaining ceramic parts [1]. Although dealing with polymers, laser stereolithography is also considered one of them. As opposed to polymer parts, producing ceramic parts using stereolithographic technology also includes a stage of the product thermal processing. The part made from a mixture of a photo-cured polymer and a ceramic filler undergoes annealing. In this process, the polymer binder is removed and the ceramic filler is sintered, preserving the shape and dimensions of the original part. The list of ceramic materials suitable for such products is long, but in practice very few compounds are used. These are silicon, aluminum and zirconium oxides, as well as hydroxyapatite - when it comes to medical parts [1-4].

Ceramic materials have a rather high density, especially when compared to the density of the polymer base. E.g. zirconium oxide has a density of about $6 \mathrm{~g} / \mathrm{cm}^{3}$, aluminum oxide $-3.6-4 \mathrm{~g} / \mathrm{cm}^{3}$, hydroxyapatite $-3.1-3.2 \mathrm{~g} / \mathrm{cm}^{3}$. Silicon oxide has a slightly lower density of $2.65 \mathrm{~g} / \mathrm{cm}^{3}$. The density of the most common PCRs for laser stereolithography is between 1.1 and $1.3 \mathrm{~g} / \mathrm{cm}^{3}$. The higher the density, the smaller should be the grain size of the ceramic filler in order to ensure the heterophase system stability and to prevent rapid stratification of the resulting photocurable resin. Additive technologies are based on the process of adding material to an object one layer at a time, and any uncontrolled change in material resin at the beginning and at the end of the process is undesirable. Since the filler is the only material of the part that is left after heat treatment, a reduction in its concentration in the liquid resin due to deposition may lead to the destruction of the part during annealing.

The share of a ceramic filler can reach up to $60-70 \%$ in polymer-ceramic composites with liquid component for filling the moulding. The viscosity of such resins is very high. They are not suitable for laser stereolithography units due to difficulties in forming the working layer. According to our observations, when it comes to such common fillers as silicon or aluminum oxides, the concentration of $25 \mathrm{wt} \%$ alone forms a photopolymer that will be difficult to use in stereolithography machines, with $50 \mathrm{wt} \%$ concentration making such use impossible.

The annealing stage, during which all components of the original composite are removed, except for the filler, can also provide the chemical synthesis of ceramic material. In such a case, at the end of the 
annealing process the mass of the ceramic part will be greater than the mass of the original filler. Aluminium melts at $660^{\circ} \mathrm{C}$, which is lower than the ash-free burning temperature of photopolymers. Zirconium melts at a higher temperature and oxidizes well when heated, but its density $\left(6.51 \mathrm{~g} / \mathrm{cm}^{3}\right)$ is too high to be used as a filler. Silicon is the most suitable substance in comparison to the rest mentioned above. At the high-temperature treatment stage, silicon can be transformed into an oxide, carbide, nitride

or a mixture of these compounds. Silicon is inexpensive and its density $\left(2.33 \mathrm{~g} / \mathrm{cm}^{3}\right)$ is lower than that of an oxide $\left(2.65 \mathrm{~g} / \mathrm{cm}^{3}\right)$. In case of oxidation of all the silicon contained in the initial part to a $\mathrm{SiO}_{2}$ oxide, with the growth of the molecular weight from 28 to 60 , the mass of the ceramic filler will more than double. This is equivalent to using a photocurable resin, filled with silicon oxide with a filler content of more than $50 \mathrm{wt} \%$ instead of the silicon powder with $25 \mathrm{wt} \%$. In case of the silicon nitride $\mathrm{Si}_{3} \mathrm{~N}_{4}$ formation the gain in weight is slightly lower, 1.76 times, which is still significant. The formation of silicon carbide $\mathrm{SiC}$ would provide an increase in weight by 1.3 times.

\section{Materials And Methods}

There are technologies of ceramic parts production by moulding from the silicon charge with the subsequent thermal processing, transforming pure silicon into one of the above-named connections or in their mix [5]. Molding into tooling has significant limitations on the form and complexity of the part. Laser stereolithography makes it possible to produce the required three-dimensional part of almost any complexity, with a complex internal structure.

A series of experiments was conducted in order to study the feasibility of transforming stereolithographic polymer samples, filled with silicon, into ceramic ones, including:

- studying photo-initiated polymerization of a number of oligomers with silicon powder as a filler

- sample growth from a liquid PCR with silicon powder as a filler

- sample weighing

- sample annealing (the "weighing-annealing-weighing" process for each sample was repeated several times, provided that the sample had not been destroyed, as changes in the state of the sample were observed after each annealing stage.)

- reweighting

- sample studying

The study of photopolymerization, photo-initiated by laser radiation, was carried out on the experimental stereolithographic unit (Fig.1) according to a standard procedure [6,7]. The unit is similar to commercial stereolithographic machines equipped with the build platform movement system, as well as layer formation and resin level control systems. The advantage of this unit is its total flexibility, allowing for 
changes in the technological process and the ability to conduct experiments, having both sufficient (1-2 liters) and minimal (1-2 $\left.\mathrm{cm}^{3}\right)$ amounts of the photopolymer. The study of polymerization included polymer curing by laser radiation on the PCR surface, continuously shading the surface of a known area with the subsequent measurement of the polymer film thickness.

Three different oligomers were studied as a polymerizing base:

1) polyethylene glycol dimethacrylate (with average molecular weight 700) - further PEGDA

$\mathrm{CH}_{2}=\mathrm{CH}\left(\mathrm{CH}_{3}\right)-\mathrm{CO}-\mathrm{O}-\left(\mathrm{C}_{2} \mathrm{H}_{4} \mathrm{O}-\right)_{\mathrm{n}}-\mathrm{CO}-\mathrm{CH}\left(\mathrm{CH}_{3}\right)=\mathrm{CH}_{2}$

2) oligocarbonate dimethacrylate OKM-2

$\left(\left(\mathrm{CH}_{2}=\mathrm{CH}\left(\mathrm{CH}_{3}\right)-\mathrm{CO}-\mathrm{O}-\mathrm{C}_{2} \mathrm{H}_{4} \mathrm{O}-\mathrm{CO}\right)-\mathrm{O}-\right)_{2} \mathrm{R}$, where R $-\mathrm{C}_{4} \mathrm{H}_{8}-$

3) oligoglycerol methacrylate OGM

$\mathrm{HO}-\left(\mathrm{CH}_{2}-\mathrm{CH}\left(\mathrm{CO}-\mathrm{O}-\left(\mathrm{CH}_{3}\right) \mathrm{CH}=\mathrm{CH}_{2}\right)-\mathrm{CH}_{2}-\mathrm{O}\right)_{n}-\mathrm{H}$, where $\mathrm{n}=1-3$.

For photoinitiation of polymerization, 2,2-dimethoxy 2-phenylacetophenone (Irgacure 651) was used. The silicon powder, the filler properties of which we investigated, had the purity of $99.99 \%$, and the declared grain size did not exceed 5 microns.

\section{Results And Discussion}

The obtained experimental dependencies of the cured layer thickness on the exposure dose of the laser radiation are shown in Fig. 2. These data allow us to determine the $E_{c}$ and $D_{p}$ constants, which relate the thickness of the cured layer to the exposure dose. Without the knowledge of these characteristics, most important for any stereolithographic polymer, no three-dimensional part manufacturing is possible. Having determined these constants, we proceeded to calculate the speed of the laser beam movement on the surface of the liquid resin Eq.(1), necessary to obtain a solid layer of the required thickness.

$$
v=\sqrt{\frac{2}{\pi}}\left(\frac{P}{d \cdot E_{c}}\right) \mathrm{e}^{\left(-\frac{h}{D_{p}}\right)}
$$

The other parameters in this equation are the laser power $P(\mathrm{~mW})$ and the beam diameter $\mathrm{d}(\mathrm{mm})$. The constants calculated from the experimental data are presented in Table 1. As can be seen from the $E_{c}$ value, resins with high silicon content are very energy intensive, but the use of the DPSS laser with the power up to $300 \mathrm{~mW}$ provides sufficient speed of growing the test parts.

Table 1. The constants characterizing the liquid photopolymerizing resins (the values for the resin without filler are given in parentheses) 


\begin{tabular}{|c|c|c|}
\hline Resin & $\mathrm{E}_{\mathrm{c}}, \mathrm{mJ} / \mathrm{cm}^{2}$ & $\mathrm{D}_{\mathrm{p}}, \mathrm{mm}$ \\
\hline PEGDA/Si, 38wt\% & $91(7.9)$ & $0,065(0.48)$ \\
\hline OKM-2/Si, 34wt\% & $355(10.1)$ & $0,071(0.19)$ \\
\hline $\mathrm{OGM} / \mathrm{Si}, 37 \mathrm{wt} \%$ & $154(26)$ & $0,058(0.44)$ \\
\hline
\end{tabular}

The samples were manufactured on the same experimental unit. SUOL (chamber temperature up to 1100 C) and SNOL 12/16 (chamber temperature up to 1600 C) furnaces were used for annealing the samples. Laboratory scales and Fourier spectrometer FT-801 were used to control changes in the samples.

A stereolithographic part sample under test, made from the polymer-silicon mixture, is presented in Fig.3. After removing resin remnants and post-treating the test samples in an ultraviolet chamber, they were weighed and placed in the annealing furnace. Primary annealing was carried out in the SUOL-0,25.1/12-I1 furnace, since its construction enables placing the samples in the chamber that has already been preheated to the desired temperature. In addition, this furnace allows for annealing in a quartz tube, so that the products of polymer combustion do not contaminate the working area of the furnace itself, and either go into the atmosphere or settle on the walls of the quartz tube, which is considered an expendable item. The SNOL 12/16 furnace and corundum crucibles were used for re-annealing as no more polymer combustion products were released. The experimental data obtained are presented in Tables 2-4.

Table 2. Data on the mass change of stereolithographic samples from PEGDA/Si mixture (38wt\%) after

\begin{tabular}{|c|c|c|}
\hline Mass of sample $\mathrm{m}_{1}$ (mass of contained silicon, $\mathrm{m}_{2}$ ), $\mathrm{g}$ & Type, time and temperature of annealing & Sample mass after annealing, $\mathrm{m}_{3}, \mathrm{~g}$ \\
\hline \multirow[t]{2}{*}{$0,853(0,327)$} & primary, 1.5 hours, $\left.1000^{\circ}\right]$ & 0,392 \\
\hline & re-annealing, 4 hours , $1400^{\circ}[$ & 0,619 \\
\hline \multirow[t]{3}{*}{$0,856(0,325)$} & primary, 1 hour, $1100^{\circ} \mathrm{a}$ & 0,337 \\
\hline & re-annealing, 4 hours, $1400^{\circ}[$ & 0,502 \\
\hline & re-annealing, 4 hours, $1600^{\circ}[$ & 0,594 \\
\hline \multirow[t]{2}{*}{$0,725(0,278)$} & primary, 3 hours $1100^{\circ} \square$ & 0,371 \\
\hline & re-annealing, 4 hours, $\left.1400^{\circ}\right]$ & 0,545 \\
\hline
\end{tabular}

Table 3. Data on changes in the mass of stereolithographic samples made from OKM-2/Si mixture (34wt\%) after annealing. 


\begin{tabular}{|c|c|c|}
\hline Mass of sample $m_{1}$ (mass of contained silicon, $m_{2}$ ), $g$ & Type, time and temperature of annealing & Sample mass after annealing, $\mathrm{m}_{3}, \mathrm{~g}$ \\
\hline \multirow[t]{5}{*}{$0,567(0,193)$} & primary, 4 hours, $1100^{\circ}-[$ & 0,294 \\
\hline & re-annealing, 4 hours, $\left.1200^{\circ}\right]$ & 0,308 \\
\hline & re-annealing, 4 hours, $1400^{\circ}[$ & 0,323 \\
\hline & re-annealing, 4 hours, $1600^{\circ}-[$ & 0,418 \\
\hline & re-annealing, 4 hours, $1600^{\circ}[$ & 0,436 \\
\hline \multirow[t]{7}{*}{$0,503(0,186)$} & primary, 4 hours, $1100^{\circ}-$ & 0,261 \\
\hline & re-annealing, 4 hours, $1600^{\circ}[$ & 0,328 \\
\hline & re-annealing, 4 hours, $1600^{\circ}[$ & 0,351 \\
\hline & re-annealing, 4 hours, $1600^{\circ} \square$ & 0,367 \\
\hline & re-annealing, 4 hours, $1600^{\circ}[$ & 0,381 \\
\hline & re-annealing, 4 hours, $1600^{\circ} \square$ & 0,389 \\
\hline & re-annealing, 4 hours, $\left.1600^{\circ}\right]$ & 0,401 \\
\hline
\end{tabular}

Table 4. Data on changes in the mass of stereolithographic samples made from OGM/Si mixture (37wt\%) after annealing.

\begin{tabular}{|c|c|c|}
\hline Mass of sample $m_{1}$ (mass of contained silicon, $m_{2}$ ), $g$ & Type, time and temperature of annealing & Sample mass after annealing, $\mathrm{m}_{3}, \mathrm{~g}$ \\
\hline \multirow[t]{2}{*}{$0,418(0,155)$} & primary, 4 hours, $1100^{\circ}-[$ & 0,240 \\
\hline & re-annealing, 4 hours, $1600^{\circ}[$ & 0,304 \\
\hline $0,372(0,138)$ & primary, 4 hours, $\left.1100^{\circ}\right]$ & 0,213 \\
\hline \multirow[t]{2}{*}{$1,037(0,383)$} & primary, 4 hours, $\left.1100^{\circ}\right]$ & 0,566 \\
\hline & re-annealing, 4 hours, $\left.1600^{\circ}\right]$ & 0,660 \\
\hline $0,441(0,163)$ & primary, 4 hours, $1100^{\circ} \square$ & (destroyed) \\
\hline
\end{tabular}

After primary annealing at temperatures up to $900^{\circ} \mathrm{C}$ the tested part kept its shape but the resulting product could not withstand manipulation and crumbled into powder. After primary annealing at $1000{ }^{\circ} \mathrm{C}$ the parts came out stronger and in $50 \%$ of the cases did not fall apart immediately. Increasing the temperature to $1100^{\circ} \mathrm{C}$ led in $90 \%$ of the cases to the preservation of the annealed sample, making further careful manipulations with it possible. The part geometry after annealing depends on the choice of the polymer material. For example, parts made from OKM-2 and OGM preserve the shape of the initial part without noticeable distortions during burning, while parts from PEGDA become softer when heated and start to melt before burning. In addition to the shape changes described above, other visual changes were observed in the samples after annealing:

1. After primary annealing, the parts became porous and exhibited cracks.

2. After primary annealing at temperatures up to $900^{\circ} \mathrm{C}$, the samples retained the dark colour characteristic of silicon powder.

3. After primary annealing at higher temperatures, the samples took on a blue tint.

4. When annealed again, the part obtained a gray colour, lighter than that of the silicon powder. If there were several re-annealing stages, the sample became lighter after each stage. A completely white sample was obtained as a result of multiple re-annealing phases at $1600^{\circ} \mathrm{C}$ (Fig. 4). 
5. In some cases, during the re-annealing stage, with temperature higher than the melting point of silicon $\left(1420^{\circ} \mathrm{C}\right)$ and with a large amount of free silicon remaining in the sample, silicon melted, forming melt droplets on the sample surface.

As can be seen from Tables 2.1-2.3, there is a mass loss during primary annealing, with the sample mass starting to increase at the re-annealing stage in all cases. Information on what chemical changes take place in the samples can be obtained by FT-IR spectrometry. The obtained spectra are shown in Figures 5 , 6 and 7. Fig. 5 shows FT-IR spectra of the silicon powder used as a filler and cured polymer, based on OKM-2 with silicon filler. To obtain the spectrum, the sample was milled in the mortar. The same procedure was used to obtain spectra of all the other samples. Fig. 6 shows the FT-IR spectra of samples after primary annealing at 800 and $1100{ }^{\circ} \mathrm{C}$ and after a combination of primary and repeated annealing $\left(1100^{\circ} \mathrm{C}+1600^{\circ} \mathrm{C}\right)$ processes. Fig. 7 shows the spectra of samples undergoing combined primary $\left(1100^{\circ} \mathrm{C}\right)$ and repeated $\left(1600^{\circ} \mathrm{C}\right)$ annealing, with repeated annealing of the samples performed both once and multiple times $(n=5)$.

The silicon spectrum shown in Fig. 5 has no absorption bands, and the observed small peak in the 1230 $\mathrm{cm}^{-1}$ region is associated with the phononon absorption in silicon. The polymer-silicon sample spectrum reveals that the polymer base, according to its structure, has a complex spectrum with many absorption bands. The intensity of absorption peaks is low because the polymer sample is quite soft and does not form fine powder at milling, but forms large fragments instead, which affects the observed peak intensity.

The spectrum of the sample after primary annealing at $800^{\circ} \mathrm{C}$ (Fig. 6) confirms, as expected, a significant reduction in the polymer content, but the polymer does not yet disappear entirely. The spectrum becomes similar to that of a silicon filler, but with a minimum polymer content. At this temperature, there is no noticeable interaction between silicon and atmospheric gases. The strong peaks of absorption characteristic of Si-O, Si-C or Si-N bonds are not yet noticeable against the background of polymer residues and products of incomplete combustion.

As mentioned above, primary annealing was carried out in a $50 \mathrm{~cm}$ long quartz tube. No additional ventilation of the tube took place. Since the tube was horizontal, there was no natural draught. At that time processes of thermal polymer decomposition with formation of both solid and gaseous products took place. The stream of these products makes the flow of oxygen towards the sample being annealed slightly difficult. Thus, the primary annealing process carried out in this way can be considered as oxygen-depleted annealing, at least at the initial stage of the process. It is our belief that this fact led not only to the already expected formation of silicon oxide $\mathrm{SiO}_{2}$ (peak $619 \mathrm{~cm}^{-1}$, double peak 1066 and 1094 $\mathrm{cm}^{-1}$, small peak $1200 \mathrm{~cm}^{-1}$ ) [8-15], with the primary annealing temperature increase to $1100{ }^{\circ} \mathrm{C}$ (Fig. 6), but also to the reaction of silicon with the products of incomplete polymer combustion, and, as a result, to the formation of silicon carbide $\operatorname{SiC}\left(790 \mathrm{~cm}^{-1}\right)[9,16,17]$. The blue colour of the samples obtained at this stage, typical for silicon carbide with a large amount of impurities, also confirms this assumption. 
This sample, neither containing polymer nor products of its incomplete combustion at this stage, but only the remaining silicon, silicon' oxide and carbide, was repeatedly re-annealed at $1600^{\circ} \mathrm{C}$. The FT-IR transmission spectrum of this sample (Fig. 4) can be seen in Fig. 7.

When heating a sample containing $\mathrm{Si}, \mathrm{SiO}_{2}$ and $\mathrm{SiC}$ to $1600^{\circ} \mathrm{C}$ in the presence of atmospheric oxygen, the following chemical processes may be expected. First, silicon oxidation with formation of silicon oxide (IV)

$\mathrm{Si}+\mathrm{O}_{2}=\mathrm{SiO}_{2}$

As the reaction front moves from the surface to the depth, the reaction speed decreases significantly. Under these conditions, a reaction of silicon oxide (II) formation is possible.

$\mathrm{SiO}_{2}+\mathrm{Si}=2 \mathrm{SiO}$

Silicon carbide and oxygen can also convert to silicon oxide (IV) at high temperatures.

$\mathrm{SiC}+2 \mathrm{O}_{2}=\mathrm{SiO}_{2}+\mathrm{CO}_{2}$

Moving on to the spectrum analysis of the sample that underwent primary $\left(1100^{\circ} \mathrm{C}\right)$ and repeated annealing $\left(1600^{\circ} \mathrm{C}\right)$, we note that the peaks connected to the absorption bands of silicon oxide and silicon carbide are preserved. We attribute the decrease in the intensity of the observed absorption bands to the fact that the sample hardened after a set of annealing and did not break as fast as after primary annealing. As noted earlier, the intensity of peaks depends on the dispersion degree of the powders - the smaller the particle size and packing density, the more intense peaks can be obtained.

It is noticeable that the absorption peaks at 619,1066 and $1094 \mathrm{~cm}^{-1}\left(\mathrm{SiO}_{2}\right)$ and $790 \mathrm{~cm}^{-1}(\mathrm{SiC})$ remained, while the band at $900-1200 \mathrm{~cm}^{-1}$ became slightly wider. But the main difference is the appearance of absorption peaks in the longwave region 655 and $677 \mathrm{~cm}^{-1}$. Changes in the short-wave region, namely, the intensive double peak $2342-2360 \mathrm{~cm}^{-1}$, as well as symmetric system of peaks $1400-1850 \mathrm{~cm}^{-1}$ correspond to absorption of absorbed $\mathrm{CO}_{2}$ and $\mathrm{H}_{2} \mathrm{O}$ respectively $[18,19]$, indicating high absorption capacity and high porosity of the material.

According to experimental and calculated data [20], absorption peaks in the area of $655-677 \mathrm{~cm}^{-1}$ are caused by absorption of Si-Si bond in nanoclusters of the general $\mathrm{Si}_{n} \mathrm{O}_{n}$ formula. Such clusters consist of an equal number of silicon and oxygen atoms. These clusters are formations in which the number of silicon and oxygen atoms $\mathrm{n}$ can vary from 5 to 16, excluding values 7 and 10, and contain both Si-O bonds and Si-Si bonds. The length of silicon atoms chains may contain from 2 to 4 links.

The observed widening of the short-wave wing of $900-1200 \mathrm{~cm}^{-1}$ peak seems to occur due to the appearance of a small absorption peak in the area of $1170 \mathrm{~cm}^{-1}$, typical for Si-O-C bond [13, 21, 22]. Since there is no polymer - a source of carbon - left in the sample at this point, the formation of silicon 
carboxide compounds takes place due to the reaction of silicon carbide with silicon oxide, as the reaction of silicon carbide with oxygen leads to the formation of silicon oxide and carbon dioxide only. In other words, a chain of Si-O-C-Si is being formed here[23].

Thus, we established a number of compounds that can be formed during annealing of stereolithographic polymer parts with silicon filler under conditions of free access of atmospheric air. This is mainly a mixture of oxides and silicon carbide, as well as a small amount of these two compounds' interaction product.

The current technology of ceramic part manufacturing by burning implies obtaining a porous part after the annealing stage, regardless of the part creation method, whether by molding or layer-by-layer growing. The degree of porosity of the obtained samples can be estimated by the amount of water retained by the samples. The sample based on OKM-2, taken for experiment after the two-stage annealing $(1100+1600$ $\left.{ }^{\circ} \mathrm{C}\right)$, had the mass of $0.326 \mathrm{~g}$. The sample was then submerged in water and placed in a vacuum chamber to achieve its complete degassing. After drying the sample surface with filter paper, the mass amounted to $0.688 \mathrm{~g}$. As we have already established, the sample consists mainly of silicon, silicon' oxide and carbide at this stage. The density of these substances is $2.33,2.65$ and $3.21 \mathrm{~g} / \mathrm{cm}^{3}$ respectively. Assuming the sample contains equal quantities of these substances, the calculated density of the sample equals $2.73 \mathrm{~g} / \mathrm{cm}^{3}$. The solid substance' volume in the sample is $0.119 \mathrm{~cm}^{3}$. Judging by the amount of the retained water, this volume accounts for $0.362 \mathrm{~cm}^{3}$ pores, i.e. pores occupy approximately $75 \%$ of the annealed model volume. The volume fraction of the polymer in the initial part was approximately $80 \%$.The porosity degree estimate is quite approximate, as the actual density of the may deviate from the value of $2.73 \mathrm{~g} / \mathrm{cm}^{3}$. As noted above, the spectrometric data also reveal a high porosity degree of the obtained samples, thus indirectly indicating that the model (at least in the case of polymers OKM-2 and OGM) is able to retain its dimensions and its external shape in the process of annealing quite well.

\section{Conclusions}

Thus, the series of experiments conducted confirms that obtaining ceramic parts by laser stereolithography, using silicon powder as a filler for photocurable resin, is indeed possible. This has been demonstrated on several methacrylic oligomers and their mixtures. It has been experimentally proven that in order to transform the part material from a polymer with a silicon filler into a silicon ceramic it is necessary to perform several annealing stages to remove the polymer and chemical conversion of the silicon contained. During annealing with free access to atmospheric air, the main products are a mixture of stoichiometric and non-stoichiometric oxides, as well as silicon carbide, with the mass of the ceramic sample produced being greater than the mass of the filler contained in the photopolymer. We have not found any signs of silicon interaction with atmospheric nitrogen in the presence of a more active oxidizer - i.e. oxygen. The obtained part keeps its original shape and size, contains a large number of pores and is suitable for impregnation by both resins containing silicon' carbide or oxide and resins capable of forming metal silicates during further heat treatment. 


\section{Declarations}

CRediT author statement

Michael. A. Markov: Conceptualization, Investigation, Writing - Original Draft.

Vyacheslav. V. Vnuk: Investigation.

Eugene. V. Ippolitov: Software, Resources.

Sergey. V. Kamaev: Resources, Writing - Review \& Editing.

Svetlana. A. Cherebylo: Investigation, Resources, Writing - Review \& Editing.

The authors of the article "The use of silicon powder as filler for photopolymerizing compositions in laser stereolithography and possibilities of transformation of fabricated parts from polymer to ceramics" cofirm that:

1. The article is original.

2. The article has been written by the stated authors who are ALL aware of its content and approve its submission.

The article has not been published previously

4. The article is not under consideration for publication elsewhere

5. No conflict of interest exists.

6. If accepted, the article will not be published elsewhere in the same form, in any language, without the written concent of the publisher.

\section{References}

[1] A.Zocca, P.Colombo, C.M.Gomes, J.Gunster, Additive manufacturing of ceramics: issues, potentialities, and opportunities, J. Am. Ceram. Soc. 2015, v98, №7, pp.1983-2001, D0I:10.1111/jace.1370.

[2] V.I. Putlyaev, P.V. Evdokimov, S.A. Mamonov, V.N. Zorin, E.S. Klimashkina, I.A. Rodin, T.V. Safronova, A.V. Garshev, Stereolithographic 3D printing of osteoconductive bioceramic matrices of a given shape and morphological architecture for bone regeneration, The Journal Perspektivnye Materialy (in Russian), 2019, №5, pp. 28-40.

[3] C.-J. Bae, A. Ramachandran, K. Chung, S. Park, Ceramic Stereolithography: Additive Manufacturing for 3D Complex Ceramic Structures, Journal of the Korean Ceramic Society 2017; v54 №6, pp.470-477. DOI: 10.4191/kcers.2017.54.6.12.

[4] J.W. Halloran Ceramic Stereolithography, Additive Manufacturing for ceramics by Photopolymerization, Annu. Rev. Mater. Res., 2016, v46, pp.19-40. 
[5] Patent RU 2239613 Method for producing products based on silicon nitride.

[6] A.V. Evseev, S.V. Kamaev, E.V. Kotsyuba et al. Laser technologies of rapid prototyping and direct fabrication of three-dimensional objects // Laser technologies of material processing: modern problems of fundamental research and applied development (in Russian). M: Fizmatlit, 2009, pp. 333-397.

[7] Jacobs P.F. Introduction to Rapid Prototyping and Manufacturing // Rapid Prototyping and Manufacturing: Fundamentals of Stereolithography. $1^{\text {st }}$ ed. Dearborn MI: Society of Manufacturing Engineers, 1992.

[8] V.N. Antsiferov, V.G. Gilev, V.I. Karmanov. Infrared Spectra and Structure of $\mathrm{Si}_{3} \mathrm{~N}_{4}, \mathrm{Si}_{2} \mathrm{ON}_{2}$ And Sialons Refractories and Industrial Ceramics, 2003, v44, №2, pp.108-114.

[9] S.A. Grudinkin, V.G. Golubev, A.V. Osipov, N.A. Feoktistov, S.A. Kukushkin. Infrared spectroscopy of silicon carbide layers synthesized by substitution of atoms on the surface of monocrystalline silicon, Physics of the Solid State (in Russian), 2015, v57, №12, pp. 2469-2474.

[10] N.I. Finer. From organosilicon precursor compounds to multifunctional silicon carbonitride, Russian Journal of General Chemistry (in Russian), 2012, v82, №1, pp. 47-54.

[11] N.I. Finer, M.L. Kosinova, Yu.M. Rumyantsev. Thin films of silicon and boron carbonitrides: synthesis, composition and structure research, Journal of the Russian chemical society D. I. Mendeleeva (in Russian), 2001, v XLV, № 3, pp. 101-108.

[12] A.G. Plekhanov, Plasma chemical synthesis of films of hydrogenated silicon oxycarbonitride from organosilicon compounds with nitrogen and oxygen, PhD Thesis, Nikolaev Institute of Inorganic Chemistry (NIIC) of the Siberian Branch of the Russian Academy of Sciences, Novosibirsk, 2017.

[13] N. Martinez. Wettability of Silicon, Silicon Dioxide, and Organosilicate Glass, Thesis for Degree Master of Science, University of North Texas, 2009.

[14] D. Bae. Sputtering Fabrication of Silicon Nitride and Silicon Oxide Based Dichroic Mirrors, Requirements for Degree of Bachelor of Science, Massachusetts Institute of Technology, 2015.

[15] V.A. Federiko, E.A. Fetisov, R.Z. Khafizov, G.A. Rudakov, A.A. Sigarev. Thermopile IR Sensor Arrays, Proceedings of the Scientific-Practical Conference "Research and Development - 2016", 2016, https//doi.org/10.1007/978-3-319-62870-7_5.

[16] E.P. Simonenko. New approaches to the synthesis of refractory nanocrystalline carbides and oxides and the production of ultra-high-temperature ceramic materials based on hafnium diboride, PhD Thesis, of. Kurnakova Institute of General and Inorganic Chemistry of the Russian Academy of Sciences (IGIC RAS) (in Russian), Moscow, 2016. 
[17] L.A. Ivashenko, V.I. Ivashenko, O.K. Poraba, S.M. Dub, P.L. Skrinskii, M.V. Ushakov, M.V. Karpets, A.I. Stegnii, L.A. Grishnova. HARD PLASMA CHEMICAL COATINGS BASED ON SILICON CARBON NITRIDE, Powder Metallurgy and Metal Ceramics, 2007, v46, № 11-12, pp.543-549.

[18] B. Smith, Infrared spectral interpretation, A syntematic approach, CRC Press, Florida, 1999.

[19] https://www.chromacademy.com/Ims/sco534/Infrared_Spectral_Interpretation.pdf.

[20] N.D.E. Torres, J.A.D.H.de Luna, J.M. Juarez. Theoretical and Experimental Characterization of Silicon Nanoclusters Embedded in Silicon-Rich Oxide Films, in New Research on Silicon Structure, Properties, Technology 5772/65609 ISBN: 978-953-51-3160-1 Print ISBN: 978-953-51-3159-5 eBook (PDF) ISBN: 978-953-51-4814-2 Copyright year: 2017.

[21] I.A. Averin, A.A. Karmanov, V.A. Moshnikov, I.A. Pronin, S.E. Igoshina, A.P. Sigaev, E.I. Terukov. Correlation dependences in the infrared spectra of nanostructures based on mixed oxides, Physics of the Solid State (in Russian), 2015, v57, № 12, pp. 16-24.

[22] A.H. Tavakoli, M.M. Armentrout. Hydrogenated Si-O-C nanoparticles: Synthesis, structure, and thermodynamic stability, J. Mater. Res.m v30, № 2, 2015, pp.295-303.

[23] A.V. Boyarkov, D.E. Nikolaichev, D.I. Tetelbaum, A.I. Belov, A.V. Ershov, A.N. Mikhailov. Chemical and phase composition of silicon oxide films with nanoclusters obtained by ion implantation of carbon, Physics of the Solid State (in Russian), 2012, v54, № 2, pp. 370-377.

\section{Figures}




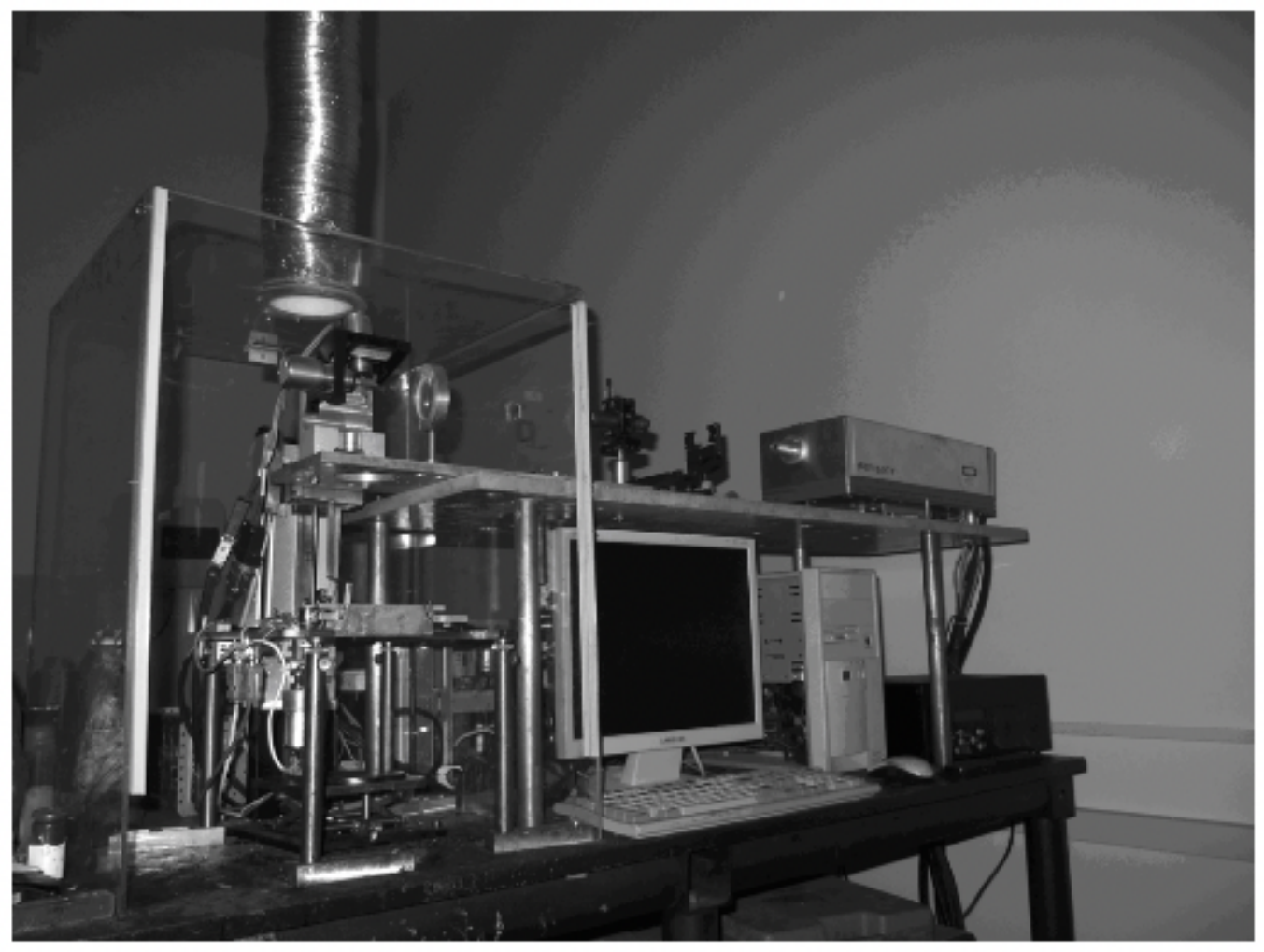

Figure 1

The experimental stereolithographic set-up

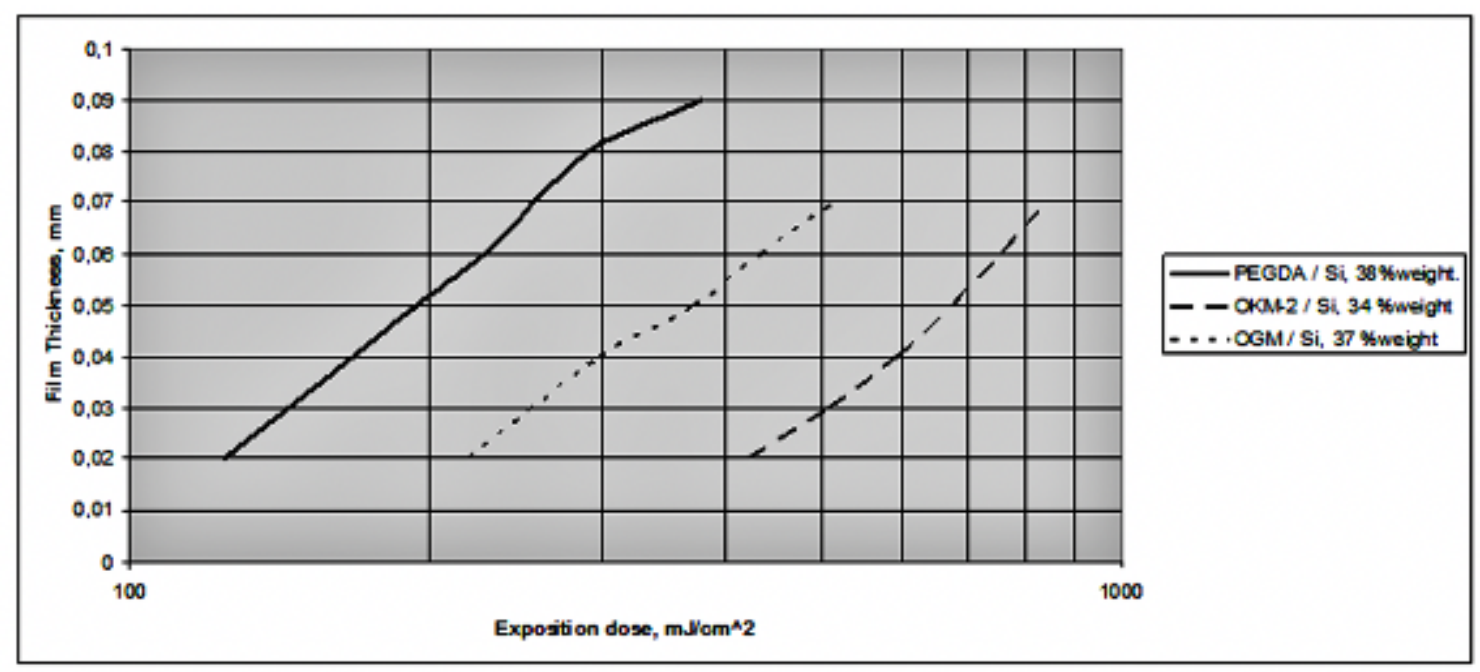

\section{Figure 2}

Experimentally obtained dependences of the film thickness of the cured resin "oligomer / silicon" $\mathrm{h}$ on the exposure dose of laser radiation $E$, when drawing with a laser beam $(\lambda=355 \mathrm{~nm})$ on the surface of the liquid resin 


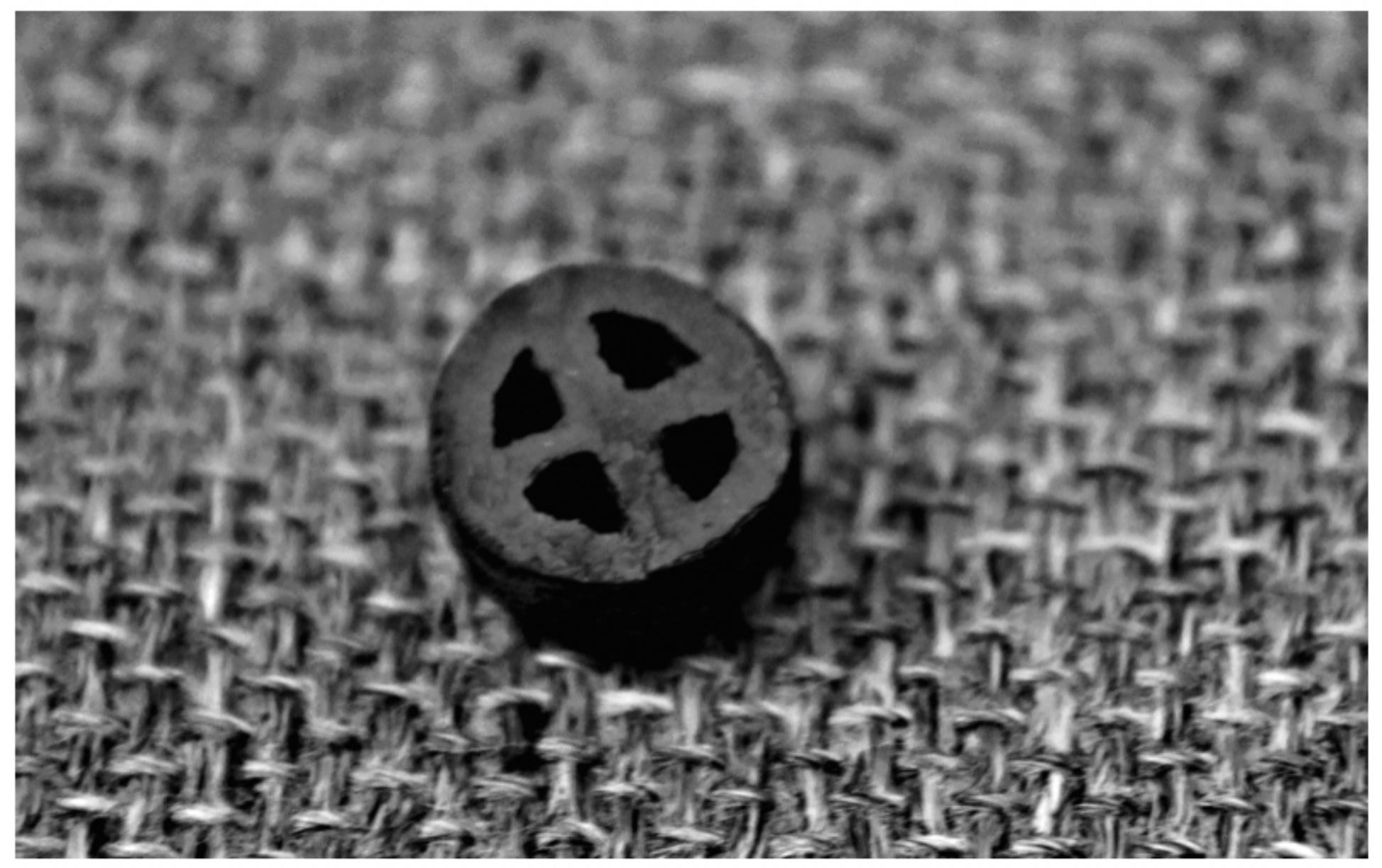

Figure 3

A test part fabricated from the mixture of "OKM-2 / silicon". The part diameter is $1 \mathrm{~cm}$ 


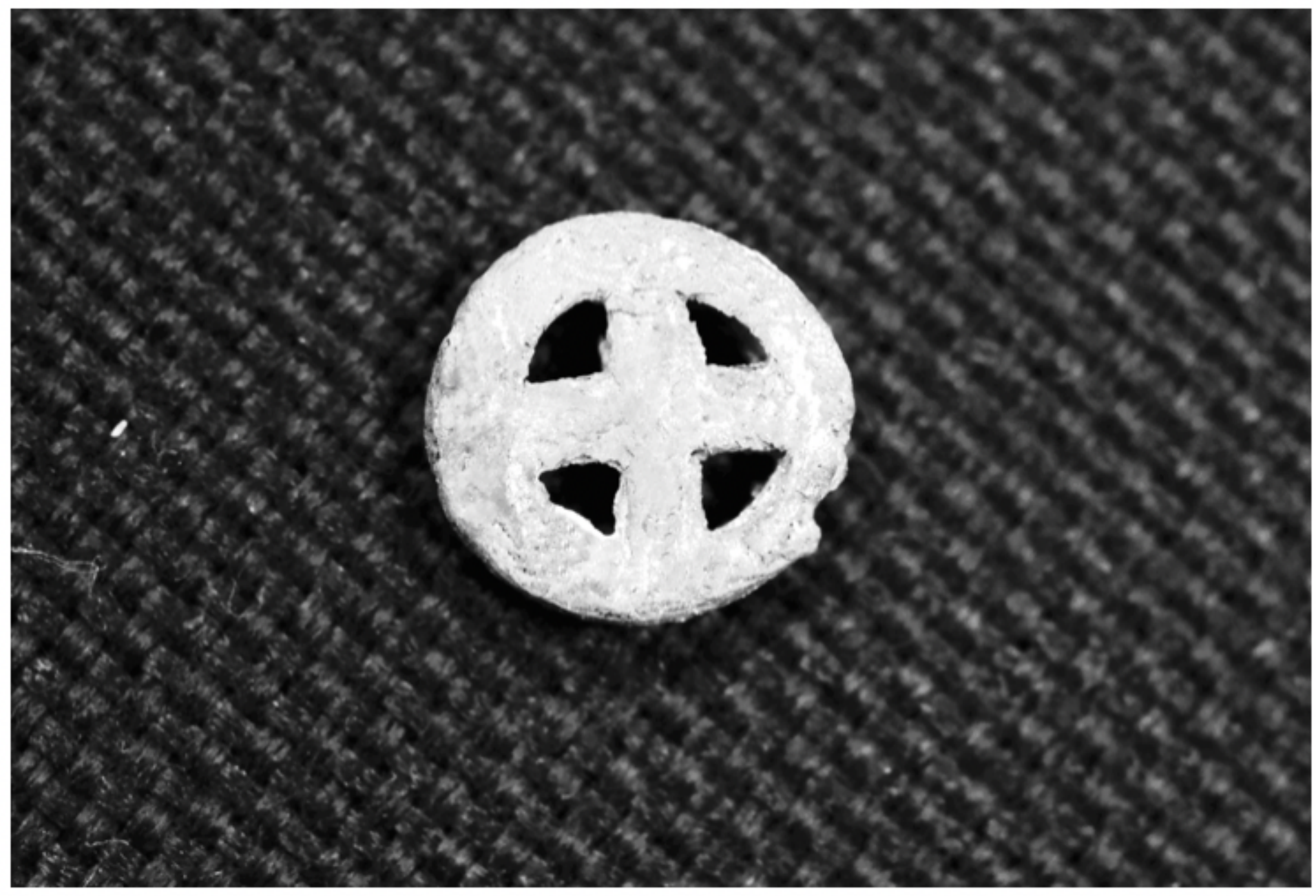

\section{Figure 4}

A test part fabricated from a mixture of "OKM-2/silicon" after repeated re-annealing. The part diameter is $1 \mathrm{~cm}$

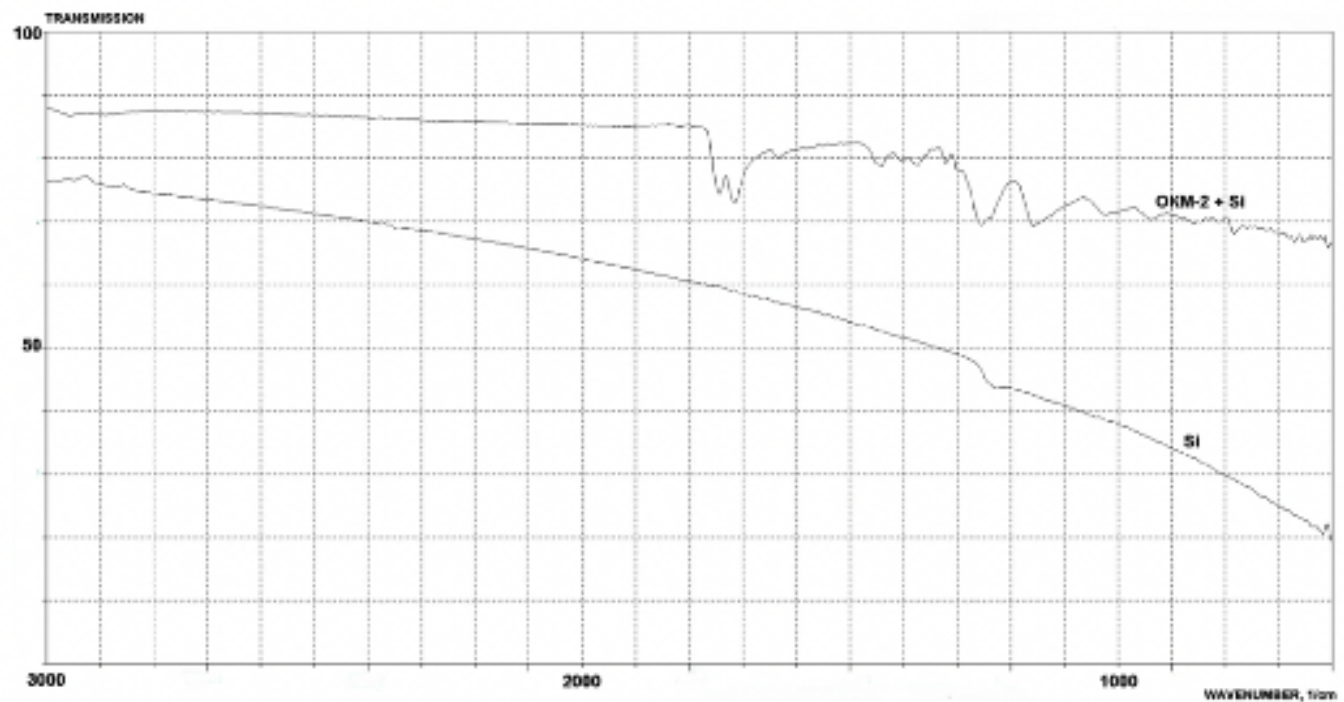

Figure 5 
IR-FT transmission spectrum of the silicon powder and the liquid resin based on OKM-2 oligomer with silicon filler

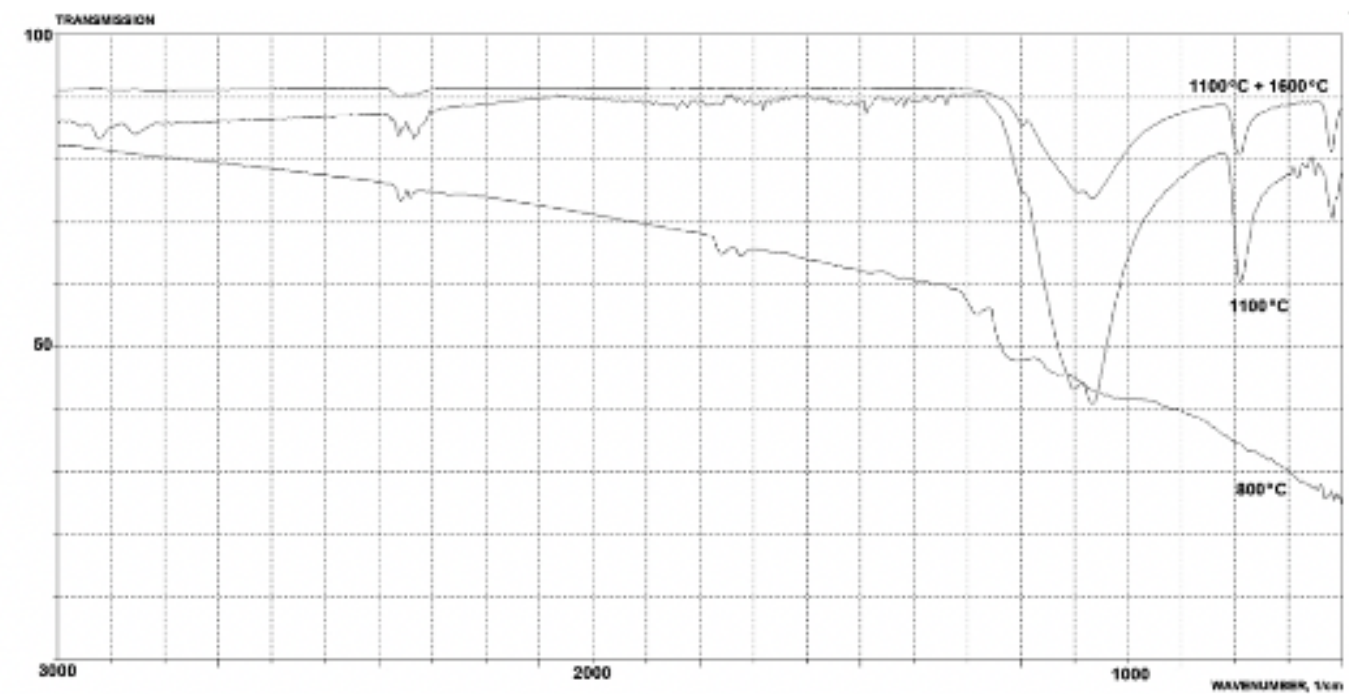

Figure 6

IR-FT spectra of the stereolithographic samples fabricated from the resin "OKM-2/Si" after primary annealing $\left(800^{\circ} \mathrm{C}\right.$ and $\left.1100^{\circ} \mathrm{C}\right)$ and after the series "primary annealing $1100^{\circ} \mathrm{C}+$ repeated annealing $1600{ }^{\circ} \mathrm{C}^{\prime \prime}$

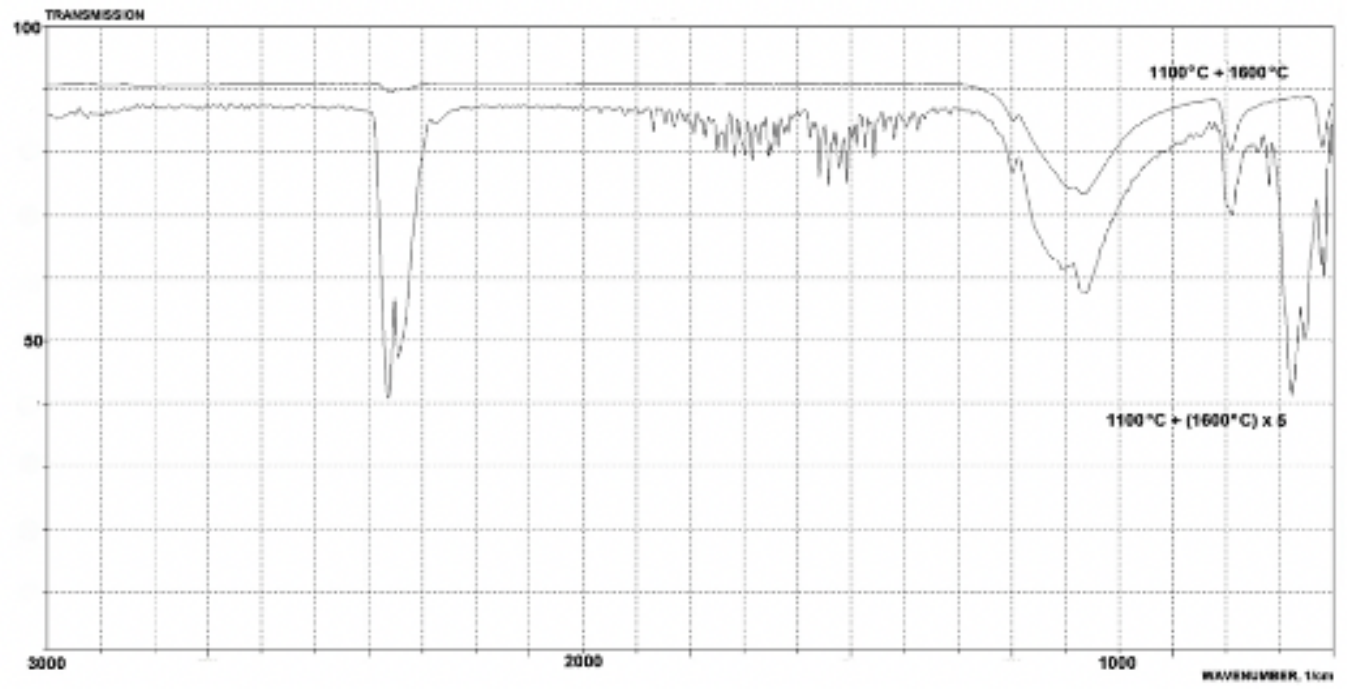

\section{Figure 7}

IR-FT spectra of the stereolithographic samples grown from the resin "OKM-2/Si" after the set "primary annealing $1100^{\circ} \mathrm{C}+$ repeated annealing $1600^{\circ} \mathrm{C}$ " and the series "primary annealing $1100{ }^{\circ} \mathrm{C}+$ fivefold repeated annealing $1600^{\circ} \mathrm{C} "$ 